\title{
ROBUST TECHNOLOGY TRANSFER POLICY MAKING USING SCENARIO BASED FUZZY TOPSIS - A CASE STUDY OF IRAN'S GAS INDUSTRY
}

\author{
SERVATI, Y. - GHODSYPOUR, S. H. ${ }^{*}$ - SHIRAZI, M. A. \\ Amirkabir University of Technology \\ 424 Hafez Ave, Tehran, Iran \\ (phone: +98-912-508-3271/216-4540; fax: +98-218-861-5482) \\ *Corresponding author \\ e-mail: Ghodsypo@aut.ac.ir \\ (phone: +98-216-454-5390; fax:+98-218-861-5482) \\ (Received $18^{\text {th }}$ Aug 2016; accepted $15^{\text {th }}$ Nov 2016)
}

\begin{abstract}
Decision making under uncertainty is one of the most important steps required for long-term development policy making. Robust policy making is the analytical framework proposed for finding stable policies to face future uncertainties. In this paper, a qualitative robust policy making mode is proposed via the application of scenario based fuzzy TOPSIS. In this study, technology transfer is categorized as complex problem with regard to the imprecise information about the future of the technology and its environment. This paper indicates how different technology transfer strategies can be ranked considering different future scenarios based on fuzzy TOPSIS. Iran gas industry is studied as a case study to rank technology transfer strategies using four future scenarios. Fuzzy TOPSIS is implemented with four similarity measures and three ideal solutions. According to overall ranking results, internal research and development $(\mathrm{R} \& \mathrm{D})$ is selected as the most appropriate technology transfer strategy for facing future uncertainties in Iran gas industry. Joint venture and license purchasing are the next two appropriate technology transfer strategies introduced to ensure faster ways of technology transfer and work force training in one hand and hedging risks of future uncertainties of the system on the other.
\end{abstract}

Keywords: robustness, technology policy making, fuzzy TOPSIS, scenario planning, gas industry

\section{Introduction}

Decision making under deep uncertainty is a new field of research for scholars facing with problems with no explicitly ascribed futures. In general, uncertainty is defined as limited knowledge about future, past or current events. In this situation no probabilities can be explicitly ascribed to parameter estimates or states of nature (Do, 2008). Technology policy making is known as an uncertain process due to rapidly changing nature of technology and rapid changes in its influential factors. Accordingly, technology policy maker should consider uncertainties in order to avoid unscheduled problems during the policy implementation phase. Technology transfer policy making is a major field of study which refers to deciding whether to make technology, buy it or to enter an alliance with respect to future uncertainties (Segal-Horn and Faulkner, 2010, Jiang et al., 2010). Thereupon, a policy maker should have a clear view of future events and needs to make policies so as to face the described future. Many scholars have used scenario planning to prepare policies for possible futures and make them more resilient and creative (Hiltunen, 2009). This method can be used to make technology transfer policies more robust to future changes of technology and its environmental uncertainties. Once scenarios are made, a tool to select the best policy against developed futures is needed. In this paper the scenario planning method is enhanced with fuzzy TOPSIS to choose robust technology transfer policy. Fuzzy TOPSIS is applied in this 
study owing to the high number of criteria and policies. The methodology is implemented in Iran gas industry as a case study to display its empirical results. Final results shows that, internal research and development (R\&D) is the most appropriate technology transfer strategy for covering future ambiguities of Iran gas industry. Joint venture and license purchasing are the next two proper technology transfer strategies.

This paper is organized as follows. It begins with a brief discussion of the technology transfer models followed by the introduction of certainty, risk and uncertainty. In the next section, scenario planning methodology is explained and its role in coping with deep uncertainty is defined. Then, fuzzy TOPSIS method is explained as a well-known Multi Objective Decision Making tool. Next section describes Qualitative robust technology transfer policy making under deep uncertainty and examines its design steps. Finally, with an empirical manner, the introduced methodology is utilized to select the most appropriate way of technology transfer in Iran gas industry considering probable futures.

\section{Literature Review}

\section{Technology transfer modes}

The definition of technology transfer differs substantially from one discipline to another (Rennkamp and Boyd, 2015). The descriptions of technology transfer can be summarized as: Technology transfer is the flow of technology and is an important means of technology development. Technology transfer is the transfer, proliferation, promotion, and transplantation of technical achievements in different countries, regions, sectors, industries, or enterprises (Audretsch et al., 2014). Figure 1 depicts overall process of technology management and technology transfer.

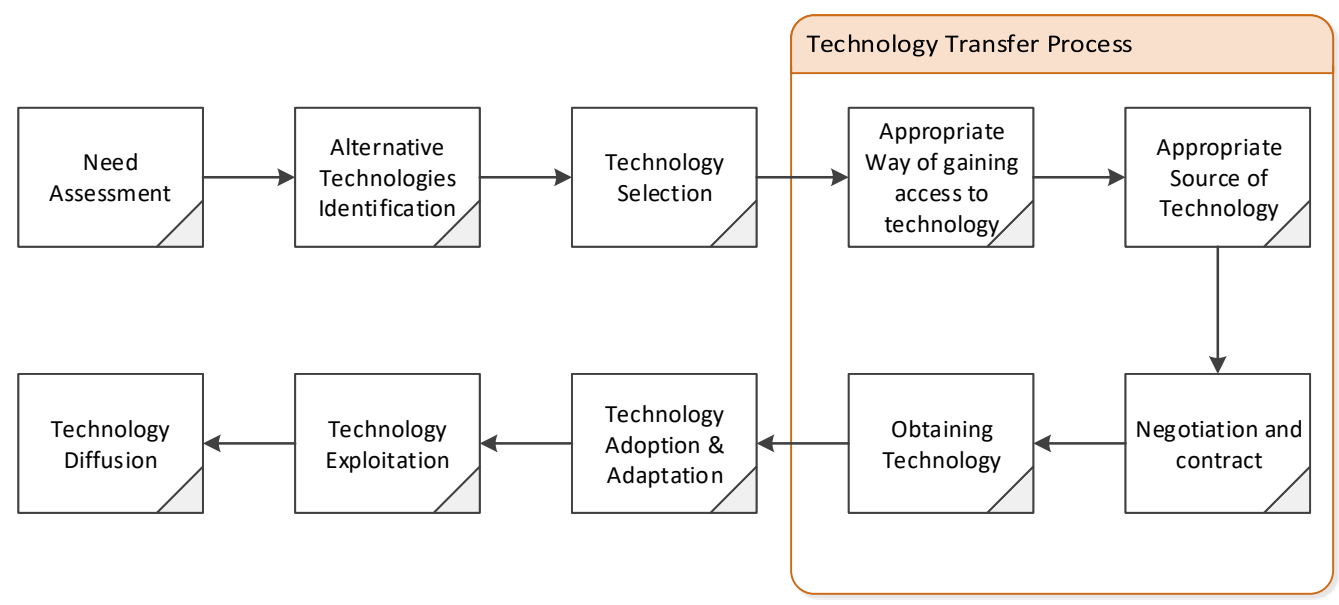

Figure 1. Overall process of Technology Management

As sketched in Figure 1 above, the core processes in technology transfer are finding an appropriate way to access the technology, reaching appropriate sources for the technology, negotiation and making contract, and finally obtaining the technology (Arasti et al., 2008). In the literature there are variety of models used for selection of technology transfer modes including positioning (Hax and Majluf, 1996, Babafemi, 
2015) resource based ones (Chiesa, 2001), dynamic (Jayaraman et al., 2004) network based ones (Theodorakopoulos et al., 2012).

According to Chiesa model (Chiesa, 2001) there are two clusters of methods for planned transfers that permit access to and use of, technological know-how:

(1) Going solo methods: these methods are based on internal functions of the system and are used in cases of availability of capabilities in the system, protection of proprietary technologies, controlling technology development and use, building and renewing capabilities and when there is lack of intellectual property rights (Jolly, 1995). An example for these methods is (Chiesa, 2001):

- Internal R\&D: R\&D and innovation procedure take place inside the system relying on internal research centers and scientists

(2) Collaborating methods: these methods are based on collaboration of two or more entities when required (Jolly, 1995):

- To Enable the firm to obtain skills or resources more quickly

- To attain some of the necessary resources and capabilities

- To have peer learning

- To share the cost and risks of projects

- To facilitate the creation of a shared standard

- To easily access a new market (Developing countries) or step into an industry

Arasti et al. (2008) introduce a comprehensive model for the selection of an appropriate mode of technology transfer on the basis of Chiesa (2001) model. In this paper, Arasti model is employed for the evaluation process.

\section{Scenario planning}

Scenarios are considered as valuable tools that help organizations to prepare for possible eventualities, and makes them more flexible and more innovative (Hiltunen, 2009). Therefore, increasing emphasis is being placed on the use of scenario planning techniques because of its usefulness in times of uncertainty and complexity (Schoemaker, 2015). It should however be mentioned that although no scenario can give us an accurate description of the future (Varum and Melo, 2010), consideration of scenarios as multiple possible future alternatives helps us make planned future policies in a holistic manner (Jetter, 2003; Burt and van der Heijden, 2003) and, hence,improving ability to deal with uncertainty and overall decision making process (Varum and Melo, 2010; Fan et al., 2015).

There are three major scenario development techniques (Durance and Godet, 2010; Bezold, 2010; Bradfield et al., 2005) in the literature. Main steps of making scenarios are shown in Figure 2. 


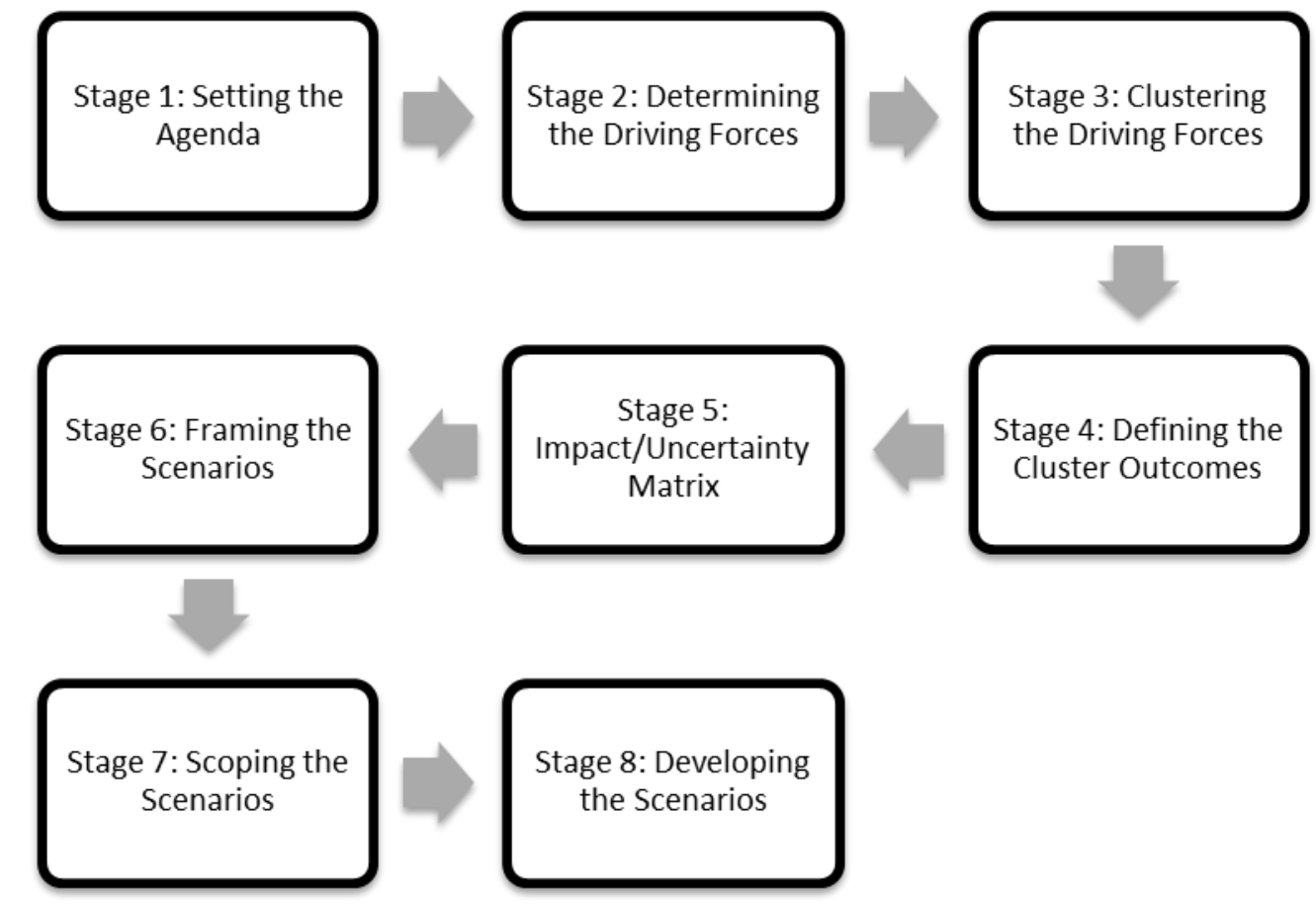

Figure 2. Overall procedure of scenario development methodology (Wright and Cairns, 2011)

\section{Fuzzy TOPSIS}

Fuzzy sets, introduced by Zadeh in 1965 (Zadeh, 1965), provide a new mathematical tool to deal with uncertainty of information. Since then, fuzzy set theory has been rapidly developed and many successful real applications of fuzzy sets and systems in wide-ranging fields have emerged (e.g. Şengül et al., 2015). A fuzzy set $\tilde{A}$ of $X$ is defined by its membership function when $X$ is a universal set.

$$
\mu_{\mathrm{X}}: \mathrm{X} \rightarrow[0,1] ; \mathrm{x} \sim \mu_{\mathrm{X}}(\mathrm{x})[0,1]
$$

The value of $\mu_{\mathrm{X}}(\mathrm{x})$ represents the grade of membership of $x$ in $X$ and is interpreted as the degree to which $x$ belongs to $\widetilde{A}$ therefore the closer the value of $\mu_{\mathbb{A}}(\mathrm{x})$ to 1 , the more its belonging to $\widetilde{\mathrm{A}}$ (Lu et al., 2007). A fuzzy set $\widetilde{\mathrm{A}}$ can be characterized as a set of ordered pairs of elements $x$ and grade $\mu_{\mathbb{\AA}}(\mathrm{x})$ and is noted as:

$$
\tilde{A}=\left[\left(x, \mu_{\AA}(\mathrm{x})\right) \| \mathrm{x} \in \mathrm{X}\right]
$$

Basic notions and Operations and properties of fuzzy sets can be found in the literature (Lu et al., 2007). Following the introduction of fuzzy sets in the following paragraphs, fuzzy TOPSIS method is briefly explained.

The Technique for Order Preferences by Similarity to an Ideal Solution (TOPSIS) was first introduced by Hwang and Yoon (1981). The main idea is to choose a solution nearest to the positive ideal solution and farthest from the negative ideal solution (Tzeng and Huang, 2011). 
The fuzzy TOPSIS Method can be implemented by the following steps (Hwang and Yoon, 1981):

Let :

$$
\begin{gathered}
C_{1} \\
C_{2} \\
\tilde{D}=\begin{array}{c}
A_{1} \\
A_{2} \\
\ldots \\
A_{m}
\end{array}\left[\begin{array}{cccc}
\tilde{x}_{11} & \tilde{x}_{12} & \ldots & C_{n} \\
\tilde{x}_{21} & \tilde{x}_{22} & \ldots & \tilde{x}_{2 n} \\
\ldots & \ldots & \ldots & \ldots \\
\tilde{x}_{m 1} & \tilde{x}_{m 2} & \ldots & \tilde{x}_{m m}
\end{array}\right] \\
\tilde{W}=\left[\begin{array}{llll}
w_{1} & w_{2} & \ldots & w_{n}
\end{array}\right]
\end{gathered}
$$

Where $\tilde{x}_{i j} \forall i j, j$ and $\widetilde{w}_{j} j=1 \ldots n$ can be linguistic variables described by any form of fuzzy numbers.

Step 1: Calculation of the importance of the criteria and the rating of alternatives with respect to each criterion:

If a decision group is assumed to have $\mathrm{K}$ persons, then the importance of the criteria and the rating of alternatives with respect to each criterion can be calculated as (Chen, 2000):

$$
\begin{aligned}
& \tilde{x}_{i j}=\frac{1}{K}\left[\tilde{x}_{i j}^{1}+\tilde{x}_{i j}^{2}+\cdots+\tilde{x}_{i j}^{k}\right] \\
& \widetilde{w}_{j}=\frac{1}{K}\left[\widetilde{w}_{j}^{1}+\widetilde{w}_{j}^{2}+\cdots+\widetilde{w}_{j}^{k}\right]
\end{aligned}
$$

Step 2: Calculating the normalized fuzzy decision matrix (FDM) $\widetilde{R}$ for trapezoidal fuzzy numbers as

$$
\widetilde{R}=\left[\tilde{r}_{i j}\right]_{m \times n}
$$

Where

$$
\begin{gathered}
\tilde{r}_{i j}=\left(\frac{a_{i j}}{d_{j}^{*}}, \frac{b_{i j}}{d_{j}^{*}}, \frac{c_{i j}}{d_{j}^{*}}, \frac{d_{i j}}{d_{j}^{*}}\right), j \in B ; \\
\tilde{r}_{i j}=\left(\frac{a_{j}^{-}}{d_{i j}}, \frac{a_{j}^{-}}{c_{i j}}, \frac{a_{j}^{-}}{b_{i j}}, \frac{a_{j}^{-}}{a_{i j}}\right), j \in C ; \\
d_{j}^{*}=\max _{i} d_{i j} \quad \text { if } j \in B \\
a_{j}^{-}=\min _{i} a_{i j} \quad \text { if } j \in C
\end{gathered}
$$

And $B$ and $C$ are the set of benefit criteria and the set of cost criteria, respectively (Chen et al., 1992). 
Step 3: Calculate the weighed normalized FDM $\tilde{V}$ as:

$$
\tilde{V}=\left[\tilde{v}_{i j}\right]_{m \times n}
$$

Where

$$
\tilde{v}_{i j}=\tilde{r}_{i j} \cdot \tilde{w}_{j}
$$

Step 4: Identifying the fuzzy positive-ideal solution (FPIS, $\tilde{A}^{*}$ ) and the fuzzy negative-ideal solution (FNIS, $\tilde{A}^{-}$) as

$$
\begin{aligned}
& \tilde{A}^{*}=\left(\tilde{v}_{1}^{*}, \tilde{v}_{2}^{*}, \ldots, \tilde{v}_{n}^{*}\right) \\
& \tilde{A}^{-}=\left(\tilde{v}_{1}^{-}, \tilde{v}_{2}^{-}, \ldots, \tilde{v}_{n}^{-}\right)
\end{aligned}
$$

There are 3 ways of defining FPIS and FNIS in the literature. Table 1 shows different methods and the formulations used in the literature. Luukka has compared these three suggestions in the literature (Luukka, 2011).

Table 1. Criteria for defining FPIS and FNIS

\begin{tabular}{|l|l|l|}
\hline developer & $\tilde{v}_{j}^{*}$ & $\tilde{v}_{j}^{-}$ \\
\hline Chen et al. (2006) & $\max _{i}\left(v_{i j 4}\right)$ & $\min _{i}\left(v_{i j 1}\right)$ \\
\hline Chen $(2000)$ & $(1,1,1,1)$ & $(0,0,0,0)$ \\
\hline Luukka (2011) & $\max _{i}\left(v_{i j}\right)$ & $\min _{i}\left(v_{i j i}\right)$ \\
\hline
\end{tabular}

Notice that the last choice of fuzzy ideal solutions is the only one that is truly a trapezoidal fuzzy number, whereas the other two choices are crisp numbers that are presented as trapezoidal fuzzy numbers.

Step 5: Calculating the similarity matrix as

$$
\begin{aligned}
& s_{i}^{*}=\sum_{j=1}^{n} S_{v}\left(\tilde{v}_{j j}, \tilde{v}_{j}^{*}\right), i=1,2, \ldots, m . \\
& s_{i}^{-}=\sum_{j=1}^{n} S_{v}\left(\tilde{v}_{j j}, \tilde{v}_{j}^{-}\right), i=1,2, \ldots, m .
\end{aligned}
$$

Where $S_{v}(\mathrm{~A}, \mathrm{~B})$ is chosen from similarity measures given in Table 2. 
Table 2. Similarity measures introduced for TOPSIS method

\begin{tabular}{|c|c|c|}
\hline $\begin{array}{c}\text { Similarity } \\
\text { measure }\end{array}$ & Formulation & Developer \\
\hline$S_{1}(A, B)$ & $\begin{array}{l}S_{1}(A, B)=\frac{1}{1+d(A, B)} \\
\mathrm{d}(\mathrm{A}, \mathrm{B})=\mathrm{P}(\mathrm{A})-\mathrm{P}(\mathrm{B}) \\
\mathrm{P}(\mathrm{x})=\frac{x_{1}+2 x_{2}+2 x_{\mathrm{g}}+x_{4}}{6}\end{array}$ & $\begin{array}{l}\text { Chen and } \\
\text { Hsieh } \\
\text { (1999), } \\
\text { Chen and } \\
\text { Chen, } \\
\text { (2003) }\end{array}$ \\
\hline$S_{2}(A, B)$ & $\begin{array}{c}S_{2}(A, B)=\left(1-\frac{\sum_{i=1}^{4}\left|a_{i}-b_{i}\right|}{4}\right)\left(1-\mid X_{a}-X_{b}\right)\left(\frac{s_{a}-s_{b}}{2}\right) \frac{\min \left(Y_{a,} Y_{b}\right)}{\max \left(Y_{a}, Y_{b}\right)} \\
s_{a}=a_{4}-a_{1}, s_{b}=b_{4}-b_{1}\end{array}$ & $\begin{array}{l}\text { Chen } \\
(2000)\end{array}$ \\
\hline$S_{3}(A, B)$ & $\begin{array}{c}S_{3}(A, B)=\left(1-\frac{\sum_{i=1}^{4}\left|a_{i}-b_{i}\right|}{4}\right)\left(\frac{\min \left(P(A), P(B)+\min \left(w_{a x} w_{b}\right)\right)}{\max \left(P(A), P(B)+\max \left(w_{a}, w_{b}\right)\right)}\right) \\
P(X)=\sqrt{\left(x_{1}-x_{2}\right)^{2}+w_{x}^{2}}+\sqrt{\left(x_{3}-x_{4}\right)^{2}+w_{x}^{2}}+\left(x_{3}-x_{2}\right)+\left(x_{4}-x_{1}\right)\end{array}$ & $\begin{array}{l}\text { Wei and } \\
\text { Chen } \\
(2009)\end{array}$ \\
\hline$S_{4}(A, B)$ & $\begin{array}{c}S_{4}(A, B)=\left(1-\frac{\sum_{i=1}^{4}\left|a_{i}-b_{i}\right|}{4}\right) \times \frac{\min (P(A), P(B)}{\max (P(A), P(B)} \times \frac{\min (A(A), A(B))+\min \left(w_{A}, w_{B}\right)}{\max (A(A), A(B))+\max \left(w_{A}, w_{B}\right)} \\
P(X)=\sqrt{\left(x_{1}-x_{2}\right)^{2}+w_{x}^{2}}+\sqrt{\left(x_{3}-x_{4}\right)^{2}+w_{x}^{2}}+\left(x_{3}-x_{2}\right)+\left(x_{4}-x_{1}\right) \\
\mathrm{A}(\mathrm{X})=\mathrm{Area}(\mathrm{X})=\frac{1}{2} w_{x}\left(x_{3}-x_{2}+x_{4}-x_{1}\right)\end{array}$ & $\begin{array}{l}\text { Hejazi et } \\
\text { al. (2011) }\end{array}$ \\
\hline
\end{tabular}

Step 6: Calculating the closeness coefficient of each alternative as

$$
C C_{i}=\frac{s_{i}^{-}}{s_{i}^{*}+s_{i}^{-}}, \quad i=1,2, \ldots, m \text {. }
$$

Closeness coefficient is calculated to determine the ranking order of all possible technology transfer methods. The closeness coefficient takes into account the similarity of the method to the FPIS and Dissimilarity to the FNIS simultaneously, by calculating the relative closeness to the fuzzy positive ideal solution.

Step 7: Ranking alternatives according to the values of $C_{i}$ in descending order and choosing an alternative with the maximum $\mathrm{CC}_{\tilde{i}}$. As already mentioned, there are 3 criteria introduced to define the ideal solution and 4 calculation methods to define closeness coefficient which in total result in 12 different sets of closeness coefficient. Collan and Luukka (2013) ranks R\&D projects in his study using these 12 sets of project ranking by definition of a triangular fuzzy number $\widetilde{R P}_{\tilde{i}}$ where:

$$
\begin{gathered}
\widetilde{R P}_{i}=\left(a_{1 i}, a_{2 i}, a_{3 i}\right) \\
a_{1 i}=\min _{j} R P_{i j} \\
a_{2 i}=\operatorname{mean}_{j} R P_{i j} \\
a_{3 i}=\max _{j} R P_{i j}
\end{gathered}
$$

These fuzzy numbers can be ranked using Kaufmann and Gupta (1988) method of ranking triangular fuzzy numbers to display overall ranking of attributes. 


\section{Proposed model: Qualitative Robust Technology Transfer (QRTT) policy making under deep uncertainty}

In this paper, the model depicted in Figure 3 is utilized to make robust policies under deep uncertainty. Realization of the policy making task demonstrated in Figure 3 calls for three main steps to take.

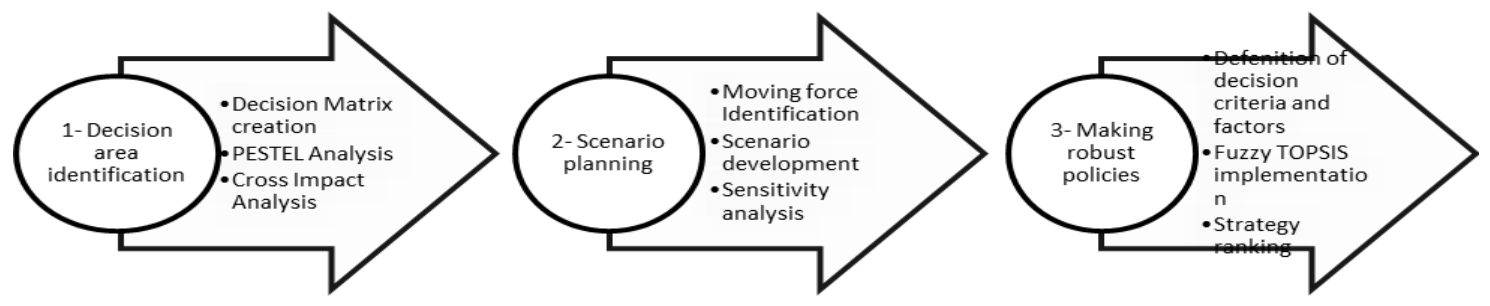

Figure 3. Proposed model for QRTT policy making under deep uncertainty

\section{Identification of decision area}

In this phase, all important information required to define the technology transfer task and major factors influencing the policy making procedure are collected. Technology transfer methods used in this paper are shown in Table 3 (Mohaghar et al., 2012; Arasti et al., 2008).

Table 3. Technology transfer strategies (TTS)

\begin{tabular}{|c|l|c|l|}
\hline 1 & Internal R\&D & 7 & Alliance \\
\hline 2 & Technology Acquisition & $\mathbf{8}$ & License purchase \\
\hline 3 & Merger & 9 & R\&D Out sourcing \\
\hline 4 & Joint venture & 10 & Minority equity \\
\hline 5 & Joint R\&D & & \\
\hline 6 & Employment and Manpower training and exchange & & \\
\hline
\end{tabular}

The task is ranking TTS so as to choose the one that performs best in all probable futures. The next step is to scan environmental components influencing technology and transfer task. PEST analysis (Political, Economic, Social and Technological analysis) describes a framework of macro-environmental factors used in the environmental scanning component of strategic management. Some analysts added Legal and rearranged the mnemonic to SLEPT, while with the incorporation of Environmental factors it was expanded to PESTEL analysis (Walsh, 2005).

After mapping most important environmental factors, the next step is to define how these factors can affect each other and make transparent view of influence map in the system. Cross Impact Analysis (CIA) is a methodology developed by Theodore Gordon and Olaf Helmer to help determine how relationships between events would impact resulting events and reduce uncertainty in the future (Servati et al., 2015). CIS exploits 
different techniques in analyzing inter-relationships by using a cross impact matrix , as a tool for systematic description of all potential modes of interaction between a given set of variables and assessment of the strength of these interactions (Schlange and Jüttner, 1997). Several versions of CIA have been developed by researchers that can be used in this step (Linss and Fried, 2010; Asan et al., 2004; Servati et al., 2015).

\section{Building technology environment future scenarios}

Scenario planning as a systematic process to define plausible boundaries of future states of the world is particularly useful in environments where deep uncertainty prevails. It aims to identify and create robust strategic options (Ram and Montibeller, 2012). In this phase, scenario planning takes place by performing Figure 2 steps.

\section{Making robust technology transfer policies using Fuzzy TOPSIS}

TTS can be ranked through fuzzy TOPSIS considering developed scenarios for the system. In order to do so, technology transfer criteria and factors are required to evaluate each strategy according to these factors in each scenario. Overall ranking outcomes of running the model indicates strategies that best overcome barriers of scenarios and have the most rewarding outputs with respect to evaluation criteria and factors.

\section{Illustrative example}

In order to realize the evaluation of introduced methodology outcomes, the method is implemented to make robust technology transfer policies for Iran gas industry using prepared normative scenarios (Ghalambor et al., 2012) and adopted technology transfer criteria (Mohaghar et al., 2012; Morrissey and Almonacid, 2005; Yang and Maskus, 2009; Jayaraman et al., 2004; Saad et al., 2002) which are mentioned in the literature.

\section{Scenarios for Iran gas industry}

Scenarios used in this paper are developed using two important moving forces of Iran gas industry: Political relations and government's dependence on petroleum. These two moving forces are selected out of 235 factors in economical, political , social, legal, environmental, and technological areas (Ghalambor et al., 2012). Figure 4 sketches overall characteristics of utilized scenarios.

In the Playful Rabbit scenario, there are many tensions in Iran political relations. In this scenario, Iran will cooperate strategically with the countries which demand its resources and stand against the opposing superpowers. Low investment in petroleum products and high dependence of the government's budget on petroleum are other signs of this scenario. In the Runaway Snake scenario, there are severe tensions among Iran and other countries. Moreover, rapid growth of using alternative fuels occurs on one hand and reduced dependence of the government's budget on oil will happen on the other.

According to Noble Horse scenario, Iran has access to pioneer technologies and is able to guarantee a safe investment in the country. Moreover, as consumption of alternative fuels rapidly grows throughout the world, the government reduces its reliance on oil. Finally, in the Sleeping Lion scenario, Iran has good political relations, and due to the increase in oil price and, hence, proliferation of oil revenue share in government's budget, rapid growth of technology is expected. 


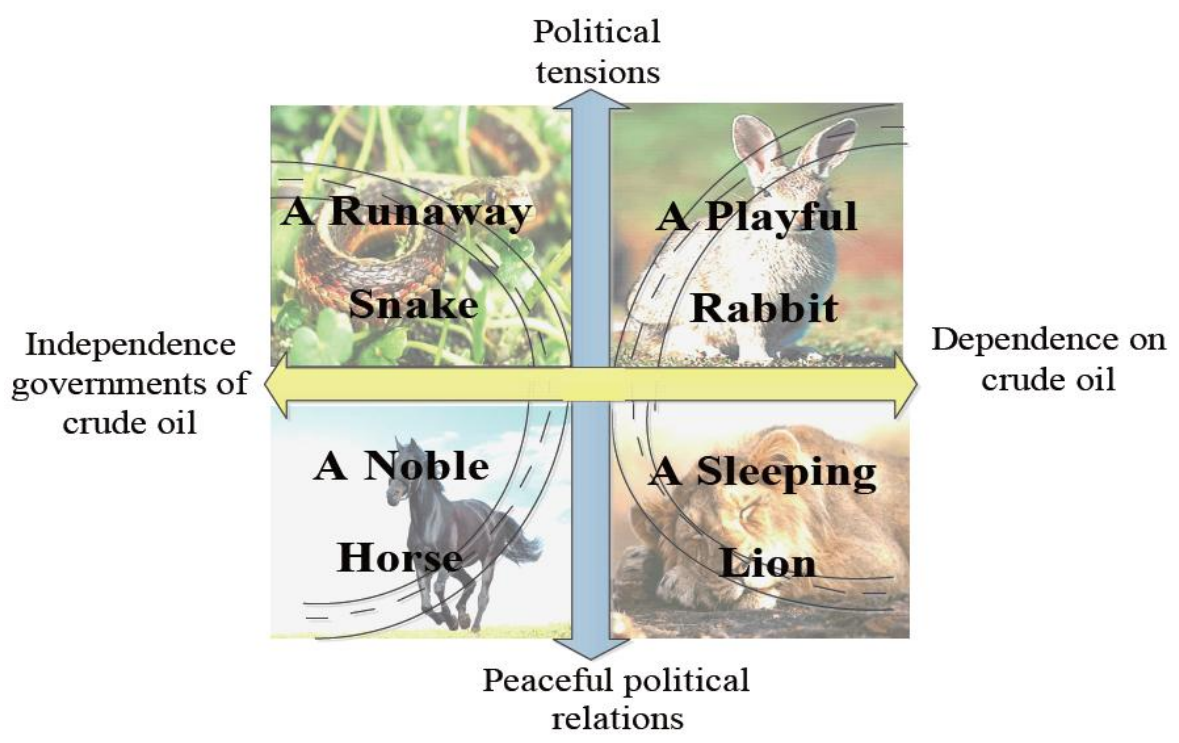

Figure 4. Scenarios facing Iran Gas industry (Ghalambor et al., 2012).

\section{Oil and gas technology transfer criteria and factors}

Evaluation of technology transfer requires criteria that are specific to the manufacture, application and transfer process of technologies (Metz and Turkson, 2000). Technology transfer process enjoys its own factors in evaluating the best transfer method. Table 4 shows different factors and suggested methods for evaluation of transfer mode of technology in oil and gas process. Regarding these factors and suggested methods, TTS are evaluated with respect to introduced scenarios. Accordingly, data collection is performed by 30 questionnaires. The questioners are distributed among the managers of oil and gas companies with total 26 completed replies sent back. Arasti et al. (2008) model has been attached to the questionnaires as a complementary tool to aid managers in evaluating each strategy for technology transfer. Results can be beneficial in distinguishing strategy evaluation differences with and without using future scenarios of industry.

Table 4. Criteria and factors in the evaluation of oil and gas process technology transfer (Arasti et al., 2008; Chiesa, 2001; Tahmooresnejad et al., 2011)

\begin{tabular}{|c|c|c|}
\hline Criteria & Factor & $\begin{array}{l}\text { Abbr } \\
\text { eviati } \\
\text { on }\end{array}$ \\
\hline $\begin{array}{l}\text { Familiarity with } \\
\text { Technology and market }\end{array}$ & Familiarity with Technology and market & F1 \\
\hline \multirow[t]{2}{*}{ Nature of technology } & Technology life cycle & F2 \\
\hline & Relevance for competitive advantage & F3 \\
\hline \multirow[t]{3}{*}{ Organization } & Original country(Cultural condition) & $\mathrm{F} 4$ \\
\hline & Original country (Power and size) & F5 \\
\hline & $\begin{array}{l}\text { Willingness and ability of technology client to meet } \\
\text { requirements of technology source and control power of } \\
\text { technology owner on the way technology is used }\end{array}$ & F6 \\
\hline
\end{tabular}




\begin{tabular}{|l|l|l|}
\hline \multirow{3}{*}{$\begin{array}{l}\text { Technology client } \\
\text { policies }\end{array}$} & Assets specialization / Investment & F7 \\
\cline { 2 - 3 } & Need for technology acquisition within the organization & F8 \\
\cline { 2 - 3 } & Need to rapid access to technology & F9 \\
\cline { 2 - 3 } & Ability to protect technology & F10 \\
\cline { 2 - 3 } & Level of risk & F11 \\
\cline { 2 - 3 } & Firms ability in technology & F12 \\
\hline \multirow{2}{*}{$\begin{array}{l}\text { Good cooperation } \\
\text { between the owner and } \\
\text { the receiver of } \\
\text { technology }\end{array}$} & purpose of partnership & F13 \\
\cline { 2 - 3 } & Ability to define the terms of partnership & F14 \\
\cline { 2 - 3 } & Link with the Firm & F15 \\
\cline { 2 - 3 } & Assets Divisibility & F16 \\
\hline
\end{tabular}

\section{Results and Discussion}

The importance weights of each criterion can be assessed through either direct or indirect pairwise comparisons (Hsu and Chen, 1996). It is , accordingly, suggested that decision makers use the linguistic variables (shown in Tables 5 and 6 ) to evaluate the importance of criteria and the rating of alternatives with respect to various criteria. Table 7 shows importance weights of technology transfer evaluation factors used to rank technology transfer methods for Iran Gas industry. The next step is construction of FDM. FDM for technology transfer methods is shown in Appendix 1. The decision matrix is completed using linguistic variables shown in Table 5.

Table 5. Linguistic variables for rating appropriateness of the selected technology transfer method

\begin{tabular}{|l|l|}
\hline Linguistic variable & Fuzzy number \\
\hline Very Poor (VP) & {$[0,0,1,2,1]$} \\
\hline Poor (P) & {$[1,2,2,3,1]$} \\
\hline Medium Poor (MP) & {$[2,3,4,5,1]$} \\
\hline Fair $(\mathrm{F})$ & {$[4,5,5,6,1]$} \\
\hline Medium Good (MG) & {$[5,6,7,8,1]$} \\
\hline Good $(\mathrm{G})$ & {$[7,8,8,9,1]$} \\
\hline Very Good $(\mathrm{VG})$ & {$[8,9,10,10,1]$} \\
\hline
\end{tabular}

Table 6. Linguistic variables for importance weight of each criterion

\begin{tabular}{|l|lll|}
\hline \multicolumn{4}{|l|}{ Linguistic variables for the ratings } \\
\hline Very low (VL) & {$\left[\begin{array}{lllll}0 & 0 & 0.1 & 0.2 & 1\end{array}\right]$} \\
\hline Low (L) & {$\left[\begin{array}{lllll}0.1 & 0.2 & 0.2 & 0.3 & 1\end{array}\right]$} \\
\hline Medium low (ML) & {$\left[\begin{array}{lllll}0.2 & 0.3 & 0.4 & 0.5 & 1\end{array}\right]$} \\
\hline Medium (M) & {$\left[\begin{array}{lllll}0.4 & 0.5 & 0.5 & 0.6 & 1\end{array}\right]$} \\
\hline Medium high (MH) & {$\left[\begin{array}{llllll}0.5 & 0.6 & 0.7 & 0.8 & 1\end{array}\right]$} \\
\hline High (H) & {$\left[\begin{array}{lllll}0.7 & 0.8 & 0.8 & 0.9 & 1\end{array}\right]$} \\
\hline Very high (VH) & {$\left[\begin{array}{lllll}0.8 & 0.9 & 1.0 & 1.0 & 1\end{array}\right]$} \\
\hline
\end{tabular}


Table 7. Linguistic variables for importance weight of technology transfer evaluation factors

\begin{tabular}{|l|l|l|l|}
\hline Factor & $\begin{array}{l}\text { Importance } \\
\text { weight }\end{array}$ & Factor & $\begin{array}{l}\text { Importance } \\
\text { weight }\end{array}$ \\
\hline F1 & MH & F9 & VH \\
\hline F2 & H & F10 & M \\
\hline F3 & H & F11 & H \\
\hline F4 & MH & F12 & M \\
\hline F5 & H & F13 & MH \\
\hline F6 & VH & F14 & MH \\
\hline F7 & H & F15 & M \\
\hline F8 & MH & F16 & M \\
\hline
\end{tabular}

After the calculation of the normalized FDM and weighted normalized FDM, closeness coefficient is calculated for all combinations of three ideal solution possibilities and four similarity measure choices resulting in twelve different orders of closeness coefficient for TTS. Resulted closeness coefficient orders are shown in Table 8. These data can be used to obtain ranking of each strategy among all combinations of similarity measures and ideal solution possibilities. Results of the ranking are demonstratd in Table 9.

Table 8. closeness coefficient orders for twelve combinations of similarity measures and ideal solution possibility

\begin{tabular}{|l|l|l|l|l|l|l|l|l|l|l|l|l|}
\hline & \multicolumn{3}{|l|}{$\begin{array}{l}\text { First criteria for ideal } \\
\text { solution }\end{array}$} & \multicolumn{3}{l|}{$\begin{array}{l}\text { Second criteria for ideal } \\
\text { solution }\end{array}$} & \multicolumn{2}{l}{$\begin{array}{l}\text { Third criteria for ideal } \\
\text { solution }\end{array}$} \\
\hline TTS & $\begin{array}{l}\text { Simi } \\
=1\end{array}$ & $\begin{array}{l}\text { Simi } \\
=2\end{array}$ & $\begin{array}{l}\text { Simi } \\
=3\end{array}$ & $\begin{array}{l}\text { Simi } \\
=4\end{array}$ & $\begin{array}{l}\text { Simi } \\
=1\end{array}$ & $\begin{array}{l}\text { Simi } \\
=2\end{array}$ & $\begin{array}{l}\text { Simi } \\
=3\end{array}$ & $\begin{array}{l}\text { Simi } \\
=4\end{array}$ & $\begin{array}{l}\text { Simi } \\
=1\end{array}$ & $\begin{array}{l}\text { Simi } \\
=2\end{array}$ & $\begin{array}{l}\text { Simi } \\
=3\end{array}$ & $\begin{array}{l}\text { Simi } \\
=4\end{array}$ \\
\hline 1 & 0.46 & 0.35 & 0.42 & 0.41 & 0.43 & 0.20 & 0.30 & 0.29 & 0.49 & 0.47 & 0.47 & 0.46 \\
\hline 2 & 0.46 & 0.33 & 0.41 & 0.40 & 0.43 & 0.01 & 0.29 & 0.28 & 0.48 & 0.45 & 0.47 & 0.30 \\
\hline 3 & 0.46 & 0.34 & 0.42 & 0.41 & 0.43 & 0.18 & 0.30 & 0.29 & 0.49 & 0.46 & 0.47 & 0.46 \\
\hline 4 & 0.39 & 0.10 & 0.25 & 0.25 & 0.37 & 0.21 & 0.10 & 0.10 & 0.41 & 0.20 & 0.32 & 0.39 \\
\hline 5 & 0.43 & 0.24 & 0.34 & 0.34 & 0.40 & 0.12 & 0.21 & 0.20 & 0.45 & 0.34 & 0.40 & 0.46 \\
\hline 6 & 0.51 & 0.53 & 0.52 & 0.52 & 0.48 & 0.01 & 0.43 & 0.42 & 0.53 & 0.63 & 0.56 & 0.57 \\
\hline 7 & 0.48 & 0.42 & 0.46 & 0.46 & 0.45 & 0.28 & 0.36 & 0.35 & 0.51 & 0.54 & 0.52 & 0.52 \\
\hline 8 & 0.47 & 0.35 & 0.42 & 0.41 & 0.44 & 0.20 & 0.31 & 0.30 & 0.49 & 0.48 & 0.48 & 0.48 \\
\hline 9 & 0.40 & 0.14 & 0.28 & 0.28 & 0.38 & 0.05 & 0.14 & 0.13 & 0.42 & 0.24 & 0.35 & 0.33 \\
\hline 10 & 0.49 & 0.46 & 0.48 & 0.47 & 0.46 & 0.30 & 0.38 & 0.37 & 0.52 & 0.58 & 0.53 & 0.53 \\
\hline
\end{tabular}

As mentioned before, the next step is to form a fuzzy triangular number for each strategy using data in Table 9. In this way, the information from all of the cases are taken into consideration by forming fuzzy triangular numbers from the individual rankings. Table 10 shows triangular fuzzy numbers formed for TTS. 
Table 9. Technology transfer strategy orders for twelve combinations of similarity measures and ideal solution possibility

\begin{tabular}{|l|l|l|l|l|l|l|l|l|l|l|l|l|}
\hline & \multicolumn{9}{|l|}{$\begin{array}{l}\text { First criteria for ideal } \\
\text { solution }\end{array}$} & \multicolumn{3}{l|}{$\begin{array}{l}\text { Second criteria for ideal } \\
\text { solution }\end{array}$} \\
\hline TTS & $\begin{array}{l}\text { Simi } \\
=1\end{array}$ & $\begin{array}{l}\text { Simi } \\
=2\end{array}$ & $\begin{array}{l}\text { Simi } \\
=3\end{array}$ & $\begin{array}{l}\text { Simi } \\
=4\end{array}$ & $\begin{array}{l}\text { Simi } \\
=1\end{array}$ & $\begin{array}{l}\text { Simi } \\
=2\end{array}$ & $\begin{array}{l}\text { Simi } \\
=3\end{array}$ & $\begin{array}{l}\text { Simi } \\
=4\end{array}$ & $\begin{array}{l}\text { Sim } \\
\text { i=1 }\end{array}$ & $\begin{array}{l}\text { Simi } \\
=2\end{array}$ & $\begin{array}{l}\text { Simi } \\
=3\end{array}$ & $\begin{array}{l}\text { Simi } \\
=4\end{array}$ \\
\hline 1 & 2 & 2 & 2 & 2 & 2 & 2 & 2 & 2 & 2 & 2 & 2 & 2 \\
\hline 2 & 5 & 5 & 5 & 5 & 5 & 6 & 5 & 5 & 5 & 5 & 5 & 6 \\
\hline 3 & 4 & 4 & 4 & 4 & 4 & 5 & 4 & 4 & 4 & 4 & 4 & 4 \\
\hline 4 & 6 & 6 & 6 & 6 & 6 & 4 & 6 & 6 & 6 & 6 & 6 & 7 \\
\hline 5 & 7 & 7 & 7 & 7 & 7 & 7 & 7 & 7 & 7 & 7 & 7 & 5 \\
\hline 6 & 10 & 10 & 10 & 10 & 10 & 11 & 10 & 10 & 10 & 10 & 10 & 10 \\
\hline 7 & 8 & 8 & 8 & 8 & 8 & 8 & 8 & 8 & 8 & 8 & 8 & 8 \\
\hline 8 & 3 & 3 & 3 & 3 & 3 & 3 & 3 & 3 & 3 & 3 & 3 & 3 \\
\hline 9 & 9 & 9 & 9 & 9 & 9 & 9 & 9 & 9 & 9 & 9 & 9 & 9 \\
\hline 10 & 1 & 1 & 1 & 1 & 1 & 1 & 1 & 1 & 1 & 1 & 1 & 1 \\
\hline
\end{tabular}

Table 10. Triangular fuzzy numbers formed for TTS

\begin{tabular}{|l|l|l|l|}
\hline TTS & $\boldsymbol{\alpha}_{\mathbf{1}}$ & $\boldsymbol{a}_{\mathbf{2}}$ & $\boldsymbol{a}_{\mathbf{3}}$ \\
\hline 1 & 2.000 & 2.000 & 2.000 \\
\hline 2 & 5.000 & 5.167 & 6.000 \\
\hline 3 & 4.000 & 4.083 & 5.000 \\
\hline 4 & 4.000 & 5.917 & 7.000 \\
\hline 5 & 5.000 & 6.833 & 7.000 \\
\hline 6 & 10.000 & 10.083 & 11.000 \\
\hline 7 & 8.000 & 8.000 & 8.000 \\
\hline 8 & 3.000 & 3.000 & 3.000 \\
\hline 9 & 9.000 & 9.000 & 9.000 \\
\hline 10 & 1.000 & 1.000 & 1.000 \\
\hline
\end{tabular}

These fuzzy numbers are then ranked via Kaufmann and Gupta method (Kaufmann and Gupta, 1988) using removal criterion to make a linear order for fuzzy numbers. This linear order makes triangular fuzzy numbers in TTS comparable. Calculated values for removal criterion result in a unique linear order which makes other criterion values (the mode and divergence) not to be calculated here. Table 11 draws final ranking results for TTS using introduced method.

Pursuant to the above procedure, data for scenarios are analyzed for overall process and each scenario separately. This analysis resulted in rankings for TTS in overall process and in each scenario distinctively, which is shown in Table 12. It can be observed from Table 12 that, Internal $R \& D$ is ranked as first Technology transfer method in Playful Rabbit scenario, Where tensions in Iran's political relations and its dependence on oil is increasing. In this situation country should trust its own abilities to 
reach desired technologies. Joint $R \& D$ and joint venture are second and third orders of TTS in this scenario. These two methods can guarantee faster access to technology in one hand while raising acquisition risks considering political tensions on the other. This risk can lead to irrecoverable losses because of High dependence of the government's budget on petroleum.

Table 11. Final ranking results for TTS

\begin{tabular}{|l|l|l|}
\hline TTS & $\begin{array}{l}\text { Removal } \\
\text { criterion } \\
\text { value }\end{array}$ & Final ranking \\
\hline Internal R\&D & 1 & 1 \\
\hline Joint Venture & 2 & 2 \\
\hline $\begin{array}{l}\text { License } \\
\text { purchase }\end{array}$ & 3 & 3 \\
\hline $\begin{array}{l}\text { R\&D Out } \\
\text { sourcing }\end{array}$ & 4.29 & 4 \\
\hline Acquisition & 5.33 & 5 \\
\hline Alliance & 5.71 & 6 \\
\hline Joint R\&D & 6.42 & 7 \\
\hline Merger and & 8 & 8 \\
\hline $\begin{array}{l}\text { Employment } \\
\text { and Manpower } \\
\text { training } \\
\text { exchange }\end{array}$ & 9 & 9 \\
\hline $\begin{array}{l}\text { Minority } \\
\text { Equity }\end{array}$ & 10.29 & 10 \\
\hline
\end{tabular}

Internal R\&D is the first TTS for Runaway Snake too. That is because of importance of political tensions and high risks of not gaining technology in formal ways because of probable sanctions. Of course, joint venture as a more cooperative method is ranked second instead of joint R\&D in the Playful Rabbit scenario because of less dependence of government on oil revenues. This method can lead to faster access to the required technology, sharing the risk of technology development in both sides of the table.

Rankings in Noble Horse scenario are to some extent, equal to findings of Mohaghar et al. (2012) work in the evaluation of TTS of oil and gas process. In other words, that evaluation has been completed in Noble Horse context. In this paper, TTS regarding different scenarios to ensure making robust policies for facing future are evaluated. It should be mentioned that using selected TTS for this scenario-based access to technology is made faster considering learning procedure for the employees in joint venture method. This decision is made because of better access to pioneer technologies and the capacity of industry to guaranty a safe investment in the country and rapid growth of using alternative fuels in world market.

License purchase is the best method according to the Sleeping Lion scenario. In this scenario with reference to good political relations, increases in oil prices and, hence, an increase in oil revenue share in government's budget, rapid growth of technology occurs. Therefore, industry takes quick steps to gain new technology in the fastest ways. That is why technology acquisition has third rank in this scenario so as to ensure that faster access to technology has a bigger share in the competitive energy market of the world. 
Table 12. Attributing rankings for all scenarios

\begin{tabular}{|c|c|c|c|c|c|c|}
\hline & Attribute name & $\begin{array}{ll}\text { Scenario } & 1 \\
\text { final } & \\
\text { ranking } & \end{array}$ & $\begin{array}{ll}\text { Scenario } & 2 \\
\text { final } & \\
\text { ranking } & \end{array}$ & $\begin{array}{ll}\text { Scenario } & 3 \\
\text { final } & \\
\text { ranking } & \end{array}$ & $\begin{array}{ll}\text { Scenario } & 4 \\
\text { final } & \\
\text { ranking } & \end{array}$ & $\begin{array}{l}\text { Overall } \\
\text { ranking }\end{array}$ \\
\hline 1 & Joint Venture & 3 & 2 & 1 & 2 & 2 \\
\hline 2 & $\begin{array}{l}\text { Technology } \\
\text { Acquisition }\end{array}$ & 7 & 7 & 5 & 3 & 5 \\
\hline 3 & R\&D Out sourcing & 6 & 6 & 4 & 5 & 4 \\
\hline 4 & Alliance & 5 & 5 & 6 & 6 & 6 \\
\hline 5 & Joint R\&D & 2 & 4 & 8 & 8 & 7 \\
\hline 6 & Minority Equity & 11 & 10 & 10 & 10 & 10 \\
\hline 7 & Merger & 8 & 8 & 7 & 7 & 8 \\
\hline 8 & License purchase & 4 & 3 & 2 & 1 & 3 \\
\hline 9 & $\begin{array}{l}\text { Employment and } \\
\text { Manpower training } \\
\text { and exchange }\end{array}$ & 9 & 9 & 9 & 9 & 9 \\
\hline 10 & internal R\&D & 1 & 1 & 3 & 4 & 1 \\
\hline 11 & reverse engineering & 10 & 11 & 11 & 11 & 11 \\
\hline
\end{tabular}

Overall ranking column of all scenarios in Table 12 shows final rankings with respect to uncertainties about future changes in the Gas industry`s context. Internal $\mathrm{R} \& \mathrm{D}$ is the most appropriate TTS rank with respect to the high risks of probable political tensions in future relations of the county. These risks rise from Irrecoverable losses of unprepared Infrastructure during political tensions and probable sanctions on vital technologies. Joint venture and license purchasing are the next two TTS ranks in overall ranking, which highlight the necessity of preparing Legal and contractual Infrastructure in industry.

\section{Conclusion}

A new methodology is introduced to make robust technology transfer policies regarding all probable future scenarios. The method includes CIA, scenario planning and modified fuzzy TOPSIS method as a multi objective decision making technique in the evaluation of the most appropriate TTS. Data from Iran gas industry is utilized as an illustrative example to evaluate TTS through Playful Rabbit, Runaway Snake, Noble Horse and Sleeping Lion scenarios. TTS ranking based on all scenarios is actualized via triangular fuzzy number. Triangular fuzzy number is made through the combination of four similarity measures and three different criteria for the fuzzy positive and negative ideal solutions. Selected TTS can be applied to prepare infrastructures required in facing future uncertainties in Iran gas industry.

Data for each scenario has been analyzed separately introducing TTS rankings for each one and in overall manner. The overall ranking enables the scholars to consider the variability of the twelve combinations created due to different points of view and different scenarios.

Finally, according to overall ranking results, internal $R \& D$ is selected as the most effective TTS for facing future uncertainties of the industry. Joint venture and license 
purchasing are the next two appropriate TTS introduced to ensure faster ways of technology transfer and work force training in one hand and hedging risks of future uncertainties of the system on the other.

Acknowledgements. The authors should express their appreciation to the National Iranian Gas Company (NIGC) for funding this research, and are grateful to NIGC research staff providing required data.

\section{REFERENCES}

[1] Arasti, M.R., Modares Yazdi, M., Delavari, M. (2008): A Comprehensive Model for Selecting Appropriate Model for Selecting Appropriate Mode of Technology Transfer. Sharif Journal of Science and Technology 43: 145-153.

[2] Asan, U., Bozdag, T. E., Polat, S. (2004): A fuzzy approach to qualitative cross-impact analysis. - Omega 32(6): 443-458.

[3] Audretsch, D.B., Lehmann, E.E., Wright, M. (2014): Technology transfer in a global economy. - The Journal of Technology Transfer 39(3): 301-312.

[4] Babafemi, I. D. (2015): Corporate Strategy, Planning and Performance Evaluation: A Survey of Literature. - Journal of Management 3(1): 43-49.

[5] Bezold, C. (2010): Lessons from using scenarios for strategic foresight. Technological Forecasting and Social Change 77(9): 1513-1518.

[6] Bradfield, R., et al. (2005): The origins and evolution of scenario techniques in long range business planning. - Futures 37(8): 795-812.

[7] Burt, G., van der Heijden, K. (2003): First steps: towards purposeful activities in scenario thinking and future studies. - Futures 35(10): 1011-1026.

[8] Chen, C.H., Hsieh, H.a.S.H. (1999): Similarity of generalized fuzzy numbers with graded mean integration representation. - In 8th international fuzzy systems association world congress. ROC: Taipei, Taiwan. pp. 551-555.

[9] Chen, S.-J., Chen, S.-M. (2003): Fuzzy risk analysis based on similarity measures of generalized fuzzy numbers. - IEEE Transactions on fuzzy systems 11: 45-56.

[10] Chen, C.-T. (2000): Extensions of the TOPSIS for group decision-making under fuzzy environment. - Fuzzy Sets and Systems 114(1): 1-9.

[11] Chen, C.-T., Lin, C.-T., Huang, S.-F. (2006): A fuzzy approach for supplier evaluation and selection in supply chain management. - International Journal of Production Economics 102(2): 289-301.

[12] Chen, S. J., Hwang, C.L., Hwang, F.P. (1992): Fuzzy multiple attribute decision making: methods and applications. - Springer-Verlag.

[13] Chiesa, V. (2001): R\&D Strategy \& Organization: Managing Technical Change in Dynamic Contexts. - World Scientific Publishing Company.

[14] Collan, M., Luukka, P. (2013): Evaluating R\&D Projects as Investments by Using an Overall Ranking from Four New Fuzzy Similarity Measure Based TOPSIS Variants. IEEE Transactions on Fuzzy Systems 22(3): 505-515.

[15] Do, D. (2008): Formulating and Modelling Robust Decision-Making Problems Under Severe Uncertainty. - Honours Thesis, Department of Mathematics and Statistics, The University of Melbourne.

[16] Durance, P., Godet, M. (2010): Scenario building: uses and abuses. - Technological Forecasting and Social Change 77(9): 1488-1492.

[17] Fan, X.Z, et al. (2015): Scenario Planning of Substitution of Wind Power for Coal-Fired Power: A Case Study from the Coastal Zone of Laizhou Bay, China. - In: Advanced Materials Research. Trans Tech Publ.

[18] Ghalambor, M.A., et al. (2012): Developing Expert Scenarios Facing Iran's Petroleum Industry. - Advances in Petroleum Exploration and Development 4(1): 28-48. 
[19] Hax, A.C., Majluf, N.S. (1996): The Strategy Concept and Process: A Pragmatic Approach. - Prentice-Hall.

[20] Hejazi, S., Doostparast, A., Hosseini, S. (2011): An improved fuzzy risk analysis based on a new similarity measures of generalized fuzzy numbers. - Expert Systems with Applications 38(8): 9179-9185.

[21] Hiltunen, E. (2009): Scenarios: process and outcome. - Journal of Futures Studies 13: 151-152.

[22] Hsu, H.-M., Chen, C.-T. (1996): Aggregation of fuzzy opinions under group decision making. - Fuzzy Sets and Systems 79(3): 279-285.

[23] Hwang, C.L., Yoon, K. (1981): Multiple Attribute Decision Making: Methods and Applications. - New York Springer-Verlag.

[24] Jayaraman, V., Bhatti, M.I., Saber, H. (2004): Towards optimal testing of an hypothesis based on dynamic technology transfer model. - Applied mathematics and computation 147(1): 115-129.

[25] Jetter, A.J.M. (2003): Educating the Guess : Strategies, Concepts, and Tools for the Fuzzy Front End of Product Development. - Portland, OR, USA: Portland International Center for Management of Engineering and Technology (PICMET).

[26] Jiang, Z.-S., Hu, L.-Y., Chen, K.-K. (2010): Decisions of knowledge transfer in technology innovation alliance: a stackelberg leader-followers model. - Operational Research 10(2): 231-242.

[27] Jolly, D. (1995): Le Champ des Alliances Interentreprises. - Gestion 20(4): 40-47.

[28] Kaufmann, A., Gupta, M.M. (1988): Fuzzy Mathematical Models in Engineering and Management Science. - Elsevier.

[29] Linss, V, Fried, A. (2010): The ADVIAN $®$ classification : a new classification approach for the rating of impact factors. - Technological Forecasting \& Social Change 77(1): 110119.

[30] Lu, J., Zhang, G., Ruan, D. (2007): Multi-objective group decision making: methods, software and applications with fuzzy set techniques. - Imperial College Press.

[31] Luukka, P. (2011): Fuzzy Similarity inMulticriteria Decision-Making Problem Applied to Supplier Evaluation and Selection in Supply ChainManagement. - Advances in Artificial Intelligence.

[32] Metz, B., Turkson, J.K. (2000): Methodological and Technological Issues in Technology Transfer: A Special Report of the Intergovernmental Panel on Climate Change. Cambridge University Press.

[33] Mohaghar, A., Monawarian, A., Raassed, H. (2012): Evaluation of technology transfer strategy of petrochemical process. - The Journal of Technology Transfer 37(4): 563-576.

[34] Morrissey, M.T., Almonacid, S. ( 2005): Rethinking technology transfer. - Journal of food engineering 67(1): 135-145.

[35] Ram, C., Montibeller, G. (2012): Exploring the impact of evaluating strategic options in a scenario-based multi-criteria framework. - Technological Forecasting and Social Change 80(4):657-672.

[36] Rennkamp, B., Boyd, A. (2015): Technological capability and transfer for achieving South Africa's development goals. - Climate Policy 15(1): 12-29.

[37] Saad, M., Cicmil, S., Greenwood, M. (2002): Technology transfer projects in developing countries-furthering the Project Management perspectives. - International Journal of Project Management 20(8): 617-625.

[38] Schlange, L.E., Jüttner, U. (1997): Helping managers to identify the key strategic issues. Long Range Planning 30(5): 777-786.

[39] Schoemaker, P.J. (2015): Uncertainty, Navigating of: From Scenarios to Flexible Options. - Wiley Encyclopedia of Management.

[40] Segal-Horn, S., Faulkner, D. (2010): Understanding global strategy. - Cengage Learning EMEA. 
[41] Şengül, Ü., et al. (2015): Fuzzy TOPSIS method for ranking renewable energy supply systems in Turkey. - Renewable Energy 75: 617-625.

[42] Servati, Y., Ghodsypour, S.H., Soleimani, M. (2015): Qualitative advanced time-based impact analysis: a new cross-impact analysis method with time lag considerations. International Journal of Academic Research 7(2): 100-118.

[43] Tahmooresnejad, L., Salami, R., Shafia, M.A. (2011): Selecting the Appropriate Technology Transfer Method to Reach the Technology Localization. - In: Proceedings of the World Congress on Engineering. London, U.K.: WCE.

[44] Theodorakopoulos, N., Preciado, D.J.S., Bennett, D. (2012): Transferring technology from university to rural industry within a developing economy context: The case for nurturing communities of practice. - Technovation 32(9): 550-559.

[45] Tzeng, G.H., Huang, J.-J. (2011): Multiple attribute decision making: Methods and applications. - CRC Press.

[46] Varum, C.A., Melo, C. (2010): Directions in scenario planning literature - A review of the past decades. Futures 42(4): 355-369.

[47] Walsh, P.R. (2005): Dealing with the uncertainties of environmental change by adding scenario planning to the strategy reformulation equation. - Management Decision 43(1): 113-122.

[48] Wei, S.-H., Chen, S.-M. (2009): A new approach for fuzzy risk analysis based on similarity measures of generalized fuzzy numbers. - Expert Systems with Applications, 36(1): 589-598.

[49] Wright, G., Cairns, G. (2011): Scenario thinking: Practical approaches to the future. Palgrave Macmillan.

[50] Yang, L. Maskus, K.E. (2009): Intellectual property rights, technology transfer and exports in developing countries. - Journal of Development Economics 90(2): 231-236.

[51] Zadeh, L.A. (1965): Fuzzy sets. - Information and control 8(3): 338-353. 